\title{
Pengaruh Succession Planning, Transformational Leadership, Training Satisfaction Terhadap Turnover Intention Karyawan Pada Sektor Publik Kementerian Agama Jakarta Pusat
}

\author{
Wanggi Citra Ameliana ${ }^{1}$, Mutiara S. Panggabean ${ }^{2}$, Tiara Puspa ${ }^{3}$ \\ 1, 2, 3 Universitas Trisakti \\ 1ameliawanggi@gmail.com, 2mutiara.panggabean@trisakti.ac.id, ${ }^{3}$ tiara.puspa@trisakti.gmail.com
}

\begin{abstract}
This study tries to analyze the effect of succession planning, transformational leadership, training satisfaction on employee turnover intention in the public sector of the Central Jakarta Ministry of Religion. Responding to this study, an experiment of 120 respondents from the Central Jakarta Ministry of Religion staffing company. The sampling method uses purposive sampling and uses descriptive statistical data analysis methods (average) and multiple regression analysis. In this research, succession planning, transformational leadership, and training satisfaction, were obtained negatively towards company turnover intention in the public sector, especially succession planning. From the results of this study, it was agreed by the leadership of the company to pay more attention to succession planning or management of employee talents, allow and add training and coaching for future leaders to be more transformational to provide beneficial investments in terms of employee career development.
\end{abstract}

Keywords: succession planning, transformational leadership, training satisfaction, turnover intention

\begin{abstract}
Abstrak
Penelitian ini bertujuan untuk menganalisis pengaruh succession planning, transformational leadership, training satisfaction terhadap turnover intention karyawan pada sektor publik Kementerian Agama Jakarta Pusat. Responden dalam penelitian ini berjumlah 120 responden dari karyawan Biro Kepegawaian Kementerian Agama Jakarta Pusat. Metode pengambilan sampel menggunakan purposive sampling dan analisis yang digunakan adalah analisis regresi berganda. Dalam penelitian ini ditemukan bahwa succession planning, transformational leadership, training satisfaction berpengaruh negatif terhadap turnover intention karyawan pada sektor publik, terutama succession planning. Dari hasil penelitian ini disarankan kepada pimpinan perusahaan untuk lebih memperhatikan succession planning atau manajemen talenta karyawan, merencanakan dan menambahkan pelatihan dan pembinaan pemimpin masa depan agar lebih transformasional dengan tujuan memberikan pengembalian investasi yang bermanfaat dalam hal career development karyawan.
\end{abstract}

Kata kunci: succession planning, transformational leadership, training satisfaction, turnover intention 


\section{PENDAHULUAN}

Fenomena yang menjadi tantangan bagi organisasi saat ini salah satunya adalah fenomena War for Talent. Fenomena ini merupakan suatu keadaan dimana ketersediaan karyawan yang bertalenta dengan persyaratan keahlian dan pengalaman yang spesifik dengan pekerjaan tidak mudah didapatkan. Sehingga perlu adanya strategi yang dilakukan oleh organisasi untuk meningkatkan retensi karyawan dan menurunkan tingkat turnover karyawan khususnya karyawan yang memiliki talenta terbaik di perusahaan. Hasil studi yang dilakukan Pusat Pengkajian dan Penelitian Kepegawaian Badan Kepegawaian Negara, faktor penyebab turnover pegawai beberapa di antaranya adalah jenjang karir, bermasalah dengan pimpinan atau supervisor, ketidak-puasan, pelatihan dan pengembangan (Wahyuni, Zaika, Anwar, Brawijaya, \& Timur, 2014).

Penelitian sebelumnya mengenai praktik succession planning telah banyak dilakukan khususnya pada bisnis keluarga atau usaha keluarga. Tetapi, sedikit penelitian berkonsentrasi pada bagaimana succession planning telah berkontribusi dalam sektor publik. Selain daripada itu, belum ada penelitian yang mengkaitkan antara pentingnya pemimpin yang transformasional dan kepuasan pelatihan yang didapatkan karyawan dalam organisasi. Sektor publik yang termasuk kelompok pemerintahan umum salah satu diantaranya adalah Kementerian Agama. Kementerian Agama adalah kementerian yang bertugas menyelenggarakan pemerintahan dalam bidang agama. Berdasarkan berita yang dikutip dari JPNN.com (2018), Kementerian Agama menjadi instansi dengan jumlah PNS terbanyak yaitu 233.910 (5,38\%) dibandingkan dengan kementerian yang lainnya. Selain itu, data yang diperoleh dari Simpeg.kemenag.go.id, (2018), menunjukkan bahwa PNS Kementerian Agama paling banyak berusia antara 40-49 tahun yaitu sebanyak 109.208 orang, disusul dengan usia antara 50-57 tahun sebanyak 64.940, kemudian usia 30-39 tahun sebanyak 45.702 orang. Sedangkan PNS usia di atas 57 tahun sebanyak 5.568 orang. Hal ini menimbulkan pertanyaan seperti apakah succession planning (perencanaan suksesi) yang ada di dalam Kementerian Agama.

Davenport et al., (2012), mengungkapkan bahwa succession planning memainkan peran penting untuk dapat meningkatkan retensi karyawan sehingga tingkat turnover karyawan menjadi lebih rendah. Ali \& Mehreen, (2019), succession planning meningkatkan loyalitas karyawan, keterlibatan karyawan, dan yang terpenting dapat mengembangkan individu yang terampil dan berbakat dalam organisasi. Reeves, (2010), succession planning berperan dalam memastikan bahwa kesuksesan organisasi akan berlanjut meski individu atau pemimpin yang saat ini terlibat sudah tidak ada. Perencanaan suksesi lebih berfokus pada peningkatan keterampilan karyawan untuk mencapai tujuan organisasi. Artinya, succession planning diperlukan untuk mempersiapkan pengganti bagi kepemimpinan yang akan datang. Sehingga, succession planning ini erat kaitannya dengan kepemimpinan.

Berbicara tentang pergantian kepemimpinan maka perlu adanya penelitian tentang seperti apakah gaya kepemimpinan yang ada dalam organisasi dan bagaimana pengaruhnya terhadap kinerja dan loyalitas karyawan. Govender, (2010), penting memiliki gaya kepemimpinan yang tepat dan berkualitas yang akan meningkatkan succession planning untuk pertumbuhan masa depan organisasi. Cheung \& Wong, (2011), menemukan bahwa pemimpin transformasional berusaha untuk meningkatkan keselarasan antara organisasi dan tujuan dengan kebutuhan 
individu. Sehingga untuk memastikan pengembangan dan kemajuan organisasi, pemimpin transformasional lebih diharapkan daripada pemimpin transaksional. Gyensare, Anku-Tsede, Sanda, \& Okpoti, (2016), transformational leadership sangat penting karena memungkinkan orang dengan beragam latar belakang untuk bekerja bersama secara produktif menuju tujuan bersama.

Dalam rangka upaya mencapai suksesi kepemimpinan yang tepat dan efisien, maka organisasi perlu melakukan pengembangan Sumber Daya Manusia dalam bentuk training and development, baik secara formal ataupun informal, terprogram atau mendesak. Malek, Kline, \& DiPietro, (2018) training dan style manajemen memiliki hubungan negatif yang signifikan dengan niat turnover karyawan. Artinya, semakin baik organisasi berinvestasi untuk training karyawan maka akan ada pengurangan niat turnover karyawan di dalamnya. Dalam organisasi pemerintahan, diklat (pendidikan dan pelatihan) merupakan suatu kewajiban yang harus dilaksanakan sebelum bertugas. Oleh sebab itu, training satisfaction (kepuasan pelatihan) memiliki peran penting sebagai tolak ukur kepuasan karyawan terhadap pendidikan dan pelatihan yang diadakan oleh organisasi. Ketika karyawan merasa puas dengan pelatihan dan pengembangan kemampuan mereka, mereka akan menunjukkan perilaku yang lebih baik di tempat kerja, loyal terhadap organisasi, sehingga hal ini dapat meningkatkan retensi karyawan atau menurunkan tingkat turnover yang terjadi di dalam organisasi. Dari uraian di atas, maka penelitian ini bertujuan untuk menganalisis pengaruh succession planning, transformational leadership, training satisfaction terhadap turnover intention karyawan pada sektor publik.

Succession planning adalah lebih dari sekedar mengetahui siapa yang akan mengambil kendali manajemen perusahaan di masa depan. Ini tentang menumbuhkan bakat untuk memastikan pemimpin perusahaan masa depan dalam jangka panjang. (Z. Ali \& Mehreen, 2019; Davenport et al., 2012; Govender, 2010; Mehrabani \& Mohamad, 2011; Nissan \& Eder, 1995). Ali, Omar, \& Amin, (2013) menemukan bahwa penilaian kinerja (performance appraisal) dan perencanaan suksesi (succession planning) secara signifikan terkait dengan kinerja karyawan. Sweeney, (2013) mengemukakan bahwa succession planning berfungsi sebagai strategi pelibatan karyawan yang menciptakan paradigma pengetahuan baru, membangun loyalitas atau kesetiaan karyawan, sehingga dapat mencegah niat berpindah (turnover intentions) dan meningkatkan moral karyawan.

Transformational leadership merupakan gaya pemimpin yang penuh dengan visi, misi, kepekaan terhadap perubahan, dan tindakan yang menginspirasi karyawan, menghargai setiap progress kinerja yang dilakukan oleh karyawannya. Afzali, Motahari, \& HatamiShirkouhi, (2014); Jha \& Malviya, (2017); Tayal, Kumar Upadhya, Yadav, Rangnekar, \& Singh, (2018) menemukan bahwa terdapat hubungan yang signifikan antara transformational leadership dengan employee motivation. Cheung \& Wong, (2011), menemukan bahwa konsep kepemimpinan transformasional secara intensif efektif dalam meningkatkan kinerja karyawan. Mittal, (2016), dikemukakan bahwa gaya kepemimpinan memainkan peran penting dalam mempengaruhi keputusan karyawan tentang apakah mereka akan tetap dengan organisasi atau pergi.

Training satisfaction berkaitan dengan perasaan karyawan suka atau tidak suka, puas atau tidak puas dengan pelatihan yang diselenggarakan organisasi secara keseluruhan. 
(Huang \& Su, 2016; Memon, Sallaeh, Baharom, Md Nordin, \& Ting, 2017; Memon, Salleh, \& Baharom, 2016). Jehanzeb, Rasheed, \& Rasheed, (2013), dikatakan bahwa terdapat korelasi penting antara pelatihan dan kepuasan kerja, tepatnya karyawan yang mendapatkan training lebih termotivasi dibandingkan dengan karyawan yang tidak berpartisipasi. Amankwaa \& Anku-Tsede, (2015), turnover intention menimbulkan beberapa biaya penggantian termasuk pencarian pasar tenaga kerja eksternal, biaya pengganti karyawan potensial, seleksi antara pengganti potensial yang bersaing, biaya training pengganti secara formal dan informal sampai karyawan pengganti tersebut mencapai tingkat kinerja yang setara dengan individu yang berhenti.

Turnover intentions merupakan keinginan atau niat hati yang ingin keluar dari organisasi dengan berbagai alasan, niat untuk mencari alternative pekerjaan yang lebih baik, ataupun niat untuk berhenti atau tinggal di perusahaan saat ini (Huang \& Su, 2016; Lu, Lu, Gursoy, \& Neale, 2016; Malek et al., 2018). Menurut Mittal, (2016), turnover intentions menjadi suatu tantangan untuk organisasi yang tidak hanya berdampak pada produktifitas tetapi juga pada profit perusahaan.

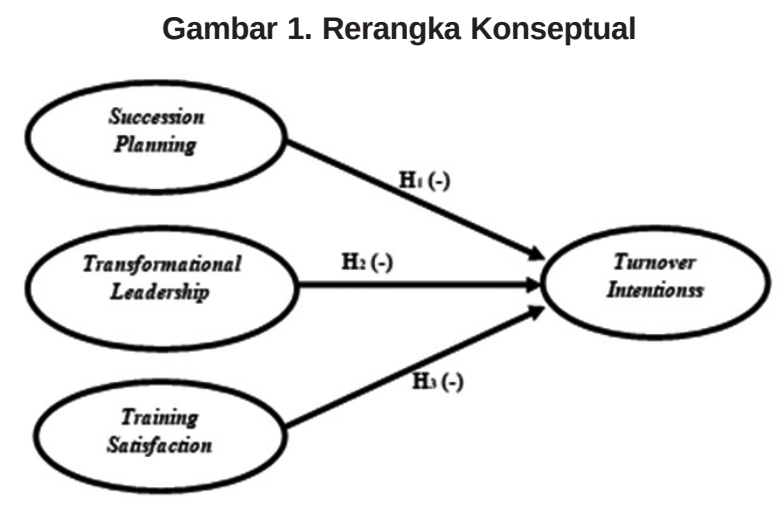

Ali \& Mehreen, (2019), Succession planning berpengaruh negatif terhadap turnover intentions pada perbankan cabang. Payne, Hovarter, Howell, Draws, \& Gieryn, (2018), succession planning mendukung kesinambungan kepemimpinan yang membawa kesuksesan dan keberlanjutan aktivitas organisasi. Lebih lanjut, mereka menyebutkan bahwa kontinuitas mengurangi biaya sumber daya manusia dalam hal turnover karyawan. Payne et al., (2018), implementasi program suksesi secara signifikan meminimalkan biaya penggantian sumber daya manusia dan menghasilkan pemimpin yang tepat untuk masa depan. Davenport, (2012), succession planning telah meningkatkan retensi karyawan sehingga tingkat turnover karyawan menjadi lebih rendah. Govender, (2010), succession planning mampu mengembangkan karyawan kepada jalur karier yang menghasilkan motivasi antar karyawan dan mengurangi tingkat turnover. Berdasarkan uraian diatas, maka hipotesis yang akan diuji:

$\mathrm{H}_{1}$ : Succession planning berpengaruh negatif terhadap turnover intentions.

(Gyensare, Kumedzro, Sanda, \& Boso, 2017), menemukan bahwa transformational leadership berpengaruh secara tidak langsung terhadap voluntary turnover intentions melalui pengaruh mediasi dari engangement dan affective organizational commitment. Gyensare et 
al., (2016), transformational leadership secara positif mempengaruhi engangement yang kemudian berhubungan negatif dengan turnover intentions. (Mittal, 2016), mengemukakan bahwa terdapat hubungan yang negatif antara transformational leadership dengan turnover intentions. Oh \& Oh, (2017), authentic leadership berpengaruh secara negatif dan siginifikan terhadap turnover intentions. Amankwaa \& Anku-Tsede, (2015), transformational leadership mengurangi turnover intention, pengaruhnya negatif dan signifikan. Berdasarkan uraian diatas, maka hipotesis yang akan diuji:

$\mathrm{H}_{2}$ : Transformational leadership berpengaruh negatif terhadap Turnover Intentions.

Memon et al., (2016), training satisfaction memiliki hubungan yang negatif dengan turnover intentions. Huang \& Su, (2016), menemukan bahwa job training satisfaction memiliki hubungan yang negatif terhadap turnover intentions. Memon et al., (2017), menemukan bahwa training satisfaction berpengaruh secara negatif dan signifikan terhadap turnover intentions. Romadhon, (2018), ditemukan bahwa training satisfaction berpengaruh secara negatif dan signifikan terhadap turnover intentions. Berdasarkan uraian diatas, maka hipotesis yang akan diuji:

$\mathrm{H}_{3}$ : Training satisfaction berpengaruh negatif terhadap turnover intentions.

\section{METODE}

Metode penelitian yang digunakan dalam penelitian ini adalah uji hipotesis (hypothesis testing). Unit analisis yang digunakan pada penelitian ini adalah karyawan sektor publik yaitu Biro Kepegawaian Kementerian Agama Jakarta Pusat, selanjutnya disebut Ropeg Kemenag. Pengambilan data dilakukan dengan cara cross sectional. Jenis penelitian yang dilakukan adalah metode kuantitatif. Variabel succession planning diukur dengan menggunakan 4 item pernyataan yang diadaptasi dari penelitian yang dilakukan oleh Ali \& Mehreen, (2019). Kemudian variabel transformational leadership diukur dengan menggunakan 15 item pernyataan yang dikembangkan dari penelitian yang dilakukan oleh Gyensare et al., (2016). Selanjutnya variable training satisfaction diukur dengan menggunakan 4 item pernyataan yang dikembangkan dari penelitian Memon et al., (2016). Dan untuk variable turnover intention diukur dengan menggunakan 4 item pernyataan yang dikembangkan dari penelitian Gyensare et al., 2016). Skala pengukuran yang digunakan untuk mengukur jawaban dari masing-masing item pernyataan khususnya variabel succession planning, transformational leadership, turnover intention adalah skala pengukuran interval berdasarkan 5 skala Likert.

Populasi dalam penelitian ini adalah seluruh karyawan pada Biro Kepegawaian Kementerian Agama Jakarta Pusat. Karyawan pada Ropeg Kemenag berjumlah 126 orang, dari 126 kuesioner yang didistribusikan sebanyak 120 kuesioner yang kembali dan bisa digunakan untuk analisis data.

Hair, et al., (2010) menyarankan nilai loading factor berdasarkan jumlah sampel, dikarenakan sampel yang digunakan dalam penelitian ini sebanyak 120 responden maka item dapat dikatakan valid apabila memiliki nilai loading factor $>0,50$ dan dikatakan tidak valid apabila memiliki nilai loading factor $<0,50$. Dasar pengambilan keputusan reliabilitas yaitu item pernyataan dapat dikatakan reliable atau layak digunakan apabila memiliki nilai 
cronbach's alpha $>0,60$ dan dikatakan tidak reliabel atau tidak layak digunakan apabila memiliki nilai cronbach's alpha $<0,60$. Hasil pengujian validitas dan reliabilitas instrumen penelitian ini dapat dilihat pada tabel 1. Menunjukkan bahwa seluruh indikator pada variabel succession planning, training satisfaction, turnover intention dinyatakan valid atau $>0,50$. Sedangkan pernyataan pada variabel transformational leadership (TLII1, TLII3, dan TLIS14) tidak valid dikarenakan $<0,50$. Nilai cronbach alpha pada setiap variabel $>0,60$ maka dinyatakan reliabel.

Table 1. Hasil Uji Validitas dan Reliabilitas Instrumen

\begin{tabular}{|c|c|c|c|c|}
\hline No. & Variabel & Pernyataan & Nilai Factor Loading & Nilai Cronbach Alpha \\
\hline \multirow{4}{*}{1.} & \multirow{4}{*}{ Succession Planning } & SP1 & 0,774 & \multirow{4}{*}{0,707} \\
\hline & & SP2 & 0,765 & \\
\hline & & SP3 & 0,668 & \\
\hline & & SP4 & 0,734 & \\
\hline \multirow{15}{*}{2.} & \multirow{15}{*}{ Transformational Leadership } & TLII1 & 0,416 & \multirow{15}{*}{0,921} \\
\hline & & TLII2 & 0,584 & \\
\hline & & TLII3 & 0,395 & \\
\hline & & TLII4 & 0,848 & \\
\hline & & TLII5 & 0,579 & \\
\hline & & TLIM6 & 0,829 & \\
\hline & & TLIM7 & 0,843 & \\
\hline & & TLIM8 & 0,859 & \\
\hline & & TLIM9 & 0,871 & \\
\hline & & TLIS10 & 0,828 & \\
\hline & & TLIS11 & 0,702 & \\
\hline & & TLIS12 & 0,838 & \\
\hline & & TLIS13 & 0,779 & \\
\hline & & TLIC14 & 0,359 & \\
\hline & & TLIC15 & 0,748 & \\
\hline \multirow{4}{*}{3.} & \multirow{4}{*}{ Training Satisfaction } & TS1 & 0,893 & \multirow{4}{*}{0,883} \\
\hline & & TS2 & 0,901 & \\
\hline & & TS3 & 0,836 & \\
\hline & & TS4 & 0,814 & \\
\hline \multirow{4}{*}{4.} & \multirow{4}{*}{ Turnover Intention } & TOI1 & 0,688 & \multirow{4}{*}{0,703} \\
\hline & & TOI2 & 0,654 & \\
\hline & & тOІ3 & 0,824 & \\
\hline & & TOI4 & 0,746 & \\
\hline
\end{tabular}




\section{HASIL DAN PEMBAHASAN}

Dalam penelitian ini karakteristik responden digambarkan berdasarkan gender, usia, tingkat pendidikan terakhir dan lama bekerja, sebagai berikut:

Tabel 2. Karakteristik Responden Penelitian

\begin{tabular}{|c|c|c|c|}
\hline No. & \multicolumn{3}{|c|}{ Berdasarkan Gender } \\
\hline 1. & Pria & 74 & $62 \%$ \\
\hline 2. & Wanita & 46 & $38 \%$ \\
\hline No. & \multicolumn{3}{|c|}{ Berdasarkan Usia } \\
\hline 1. & $<24$ tahun & 0 & 0 \\
\hline 2. & 24-39 tahun & 45 & $38 \%$ \\
\hline 3. & 40-57tahun & 71 & $59 \%$ \\
\hline 4. & $>57$ tahun & 4 & $3 \%$ \\
\hline No. & \multicolumn{3}{|c|}{ Berdasarkan Pendidikan Terakhir } \\
\hline 1. & SMU/Sederajat & 20 & $17 \%$ \\
\hline 2. & D3/Akademi & 4 & $3 \%$ \\
\hline 3. & $\mathrm{~S} 1$ & 81 & $68 \%$ \\
\hline 4. & $\mathrm{~S} 2$ & 15 & $12 \%$ \\
\hline No. & \multicolumn{3}{|c|}{ Berdasarkan Lama Bekerja } \\
\hline 1. & 1-3 tahun & 7 & $6 \%$ \\
\hline 2. & 4-6 tahun & 5 & $4 \%$ \\
\hline 3. & 7-9 tahun & 16 & $13 \%$ \\
\hline 4. & $>10$ tahun & 92 & $77 \%$ \\
\hline
\end{tabular}

Berdasarkan tabel 2 dapat dilihat bahwa karyawan Ropeg Kemenag lebih banyak pria dibandingkan wanita, dimana jumlah karyawan pria sebanyak 74 orang (62\%) sedangkan jumlah karyawan wanita sebanyak 46 orang (38\%). Rata-rata usia responden adalah 4057 tahun yang berjumlah 71 orang dengan presentase 59\%. Sebagian besar responden merupakan lulusan Sarjana (S1) dengan jumlah 81 orang (68\%). Dan mayoritas responden dalam penelitian ini telah bekerja dengan jangka waktu lebih dari 10 tahun dengan presentase sebesar $77 \%$.

Tabel 3. Hasil Uji Hipotesis

\begin{tabular}{cccc}
\hline Hipotesis & Coefficients Beta & P-Value & Keputusan \\
\hline $\mathrm{H}_{1}$ & $-0,263$ & 0,007 & H1 diterima \\
$\mathrm{H}_{2}$ & $-0,067$ & 0,137 & H2 ditolak \\
$\mathrm{H}_{3}$ & $-0,010$ & 0,938 & H3 ditolak \\
\hline
\end{tabular}

Berdasarkan hasil pengujian hipotesis 1 diketahui bahwa nilai Coefficients Beta (Koefisien Regresi) -0,263 (negatif) dan $p$-value 0,007<0,05. Hal ini menunjukkan bahwa $\mathrm{H}_{1}$ 
diterima artinya terdapat pengaruh negatif succession planning terhadap turnover intentions karyawan pada Kementerian Agama Jakarta Pusat. Hasil dari penelitian ini didukung penelitian sebelumnya yang dilakukan oleh Ali \& Mehreen, (2019), menganalisis 239 karyawan pada bank komersial dari sebuah kota besar di Pakistan. Memahami succession planning sebagai suatu strategi yang dapat memerangi turnover intention karyawan. Hal ini menunjukkan karyawan yang sudah memahami succession planning dengan baik maka akan lebih termotivasi untuk mengembangkan karir ke jenjang yang lebih baik, merasa memiliki kesempatan yang setara dan terbuka untuk dapat mengisi posisi strategis di organisasi, memperoleh sarana untuk aktualisasi diri, memperoleh manfaat pendampingan yang intensif dari pimpinan sebelumnya atau mentor, dan membangun trust karyawan terhadap organisasi sehingga hal ini dapat meningkatkan loyalitas dan menurunkan tingkat turnover intention karyawan.

Berdasarkan hasil pengujian hipotesis 2 di atas dapat diketahui bahwa nilai Unstandardized Coefficients (Koefisien Regresi) -0,067 (negatif) dan $p$-value 0,137>0,05. Hal ini menunjukkan bahwa $\mathrm{H}_{2}$ ditolak artinya tidak terdapat pengaruh negatif yang signifikan transformational leadership terhadap turnover intentions karyawan pada Kementerian Agama Jakarta Pusat. Hasil dari penelitian ini didukung penelitian sebelumnya yang dilakukan oleh Long, Thean, Ismail, \& Jusoh, (2012), dengan meneliti hubungan antara gaya kepemimpinan dan turnover intention karyawan di antara staf akademik sebuah perguruan tinggi di Malaysia. Menemukan bahwa transformational leadership berpengaruh negatif namun tidak signifikan terhadap turnover intention. Selanjutnya Gul, et al., 2003 dalam Amankwaa \& Anku-Tsede, (2015), menyelidiki hubungan antara gaya kepemimpinan, komitmen organisasi dan turnover intention, terungkap bahwa terdapat hubungan negatif tetapi tidak signifikan antara transformational leadership dan turnover intention karyawan.

Berdasarkan hasil pengujian hipotesis 3 diketahui bahwa nilai Coefficients Beta (Koefisien Regresi) -0,010 dan $p$-value 0,938>0,05. Hal ini menunjukkan bahwa $\mathrm{H}_{3}$ ditolak artinya tidak terdapat pengaruh negatif yang signifikan training satisfaction terhadap turnover intentions karyawan pada Kementerian Agama Jakarta Pusat.

Hasil dari penelitian ini menunjukkan bahwa karakteristik pemimpin tidak menjadi masalah yang berpengaruh besar terhadap keinginan karyawan untuk pindah dari perusahaan (turnover intention). Karyawan akan tetap bertahan dengan pekerjaannya meski pimpinan mereka tidak mencerminkan jiwa transformational di dalam bekerja. Kemudian, dapat disimpulkan bahwa meski karyawan di Biro Kepegawaian Kementerian Agama sudah atau belum puas dengan training yang mereka peroleh dari organisasi, mereka akan tetap loyal dan tidak ingin keluar atau tidak berkeinginan untuk keluar dari organisasi, artinya turnover intention karyawan rendah. Hal ini disebabkan dan dapat dikaitkan dengan karakteristik responden yang memang mayoritas sudah memasuki usia antara 24 s.d 39 tahun yang mana pada usia ini mereka merasa bahwa pekerjaan yang mereka tekuni sudah menjadi pusat kehidupan atau dapat dikatakan sebagai tahap pemantapan pekerjaan. Bahkan sebagian besar responden sudah berusia antara 40 s.d 57 tahun, hal ini menunjukkan bahwa mayoritas karyawan Ropeg Kemenag sudah memasuki tahap pemeliharaan pekerjaan. Bekerja dalam kondisi mental dan pengalaman yang sudah sangat matang, sudah merasa nyaman dalam lingkungan kerjanya dan hampir sebagian besar usaha diarahkan untuk mempertahankan organisasinya maka dapat dikatakan wajar apabila turnover intention dalam organisasi tetap 
rendah meski transformational leadership dan training satisfaction di dalamnya tinggi atau rendah.

\section{SIMPULAN}

Hasil pengujian $\mathrm{H}_{1}$, succession planning berpengaruh secara negatif dan signifikan terhadap turnover intention. Artinya semakin baik succession planning di Kementerian Agama maka semakin rendah tingkat turnover intention karyawan di dalamnya. Semakin buruk succession planning di Kementerian Agama maka semakin tinggi tingkat turnover intention di dalamnya. Hasil pengujian $\mathrm{H}_{2}$, transformational leadership berpengaruh secara negatif dan tidak signifikan terhadap turnover intentions. Dapat disimpulkan bahwa di Ropeg Kemenag, karakteristik pemimpin tidak menjadi masalah yang berpengaruh besar terhadap kinerja karyawan. Karyawan akan tetap bertahan dengan pekerjaan dan setia terhadap organisasinya meski pimpinan mereka tidak mencerminkan jiwa transformational di dalam bekerja. Hal ini erat kaitannya dengan karakteristik mayoritas responden berdasarkan usia dan lama bekerja. Hasil pengujian $\mathrm{H}_{3}$, training satisfaction berpengaruh secara negatif dan tidak signifikan terhadap turnover intention. Dapat disimpulkan bahwa meski karyawan di Ropeg Kemenag sudah atau belum puas dengan training yang mereka peroleh dari organisasi, mereka akan tetap loyal dan tidak ingin keluar atau tidak berkeinginan untuk keluar dari organisasi dalam artian turnover intention karyawan di Ropeg Kemenag rendah.

Diharapkan organisasi khususnya pimpinan, kepala bagian Biro Kepegawaian atau Biro SDM Kementerian Agama menekankan kembali tujuan dan manfaat succession planning baik untuk organisasi maupun untuk karyawan atau pegawai sendiri. Adapun alasan (tujuan) succession planning bagi organisasi dan karyawan, di antaranya: Untuk menemukan dan mempersiapkan karyawan terbaik yang akan menjadi Future Leader dan mendukung Kementerian Agama menjadi world class government institution. Untuk menemukan orang yang tepat dan tersedia pada waktu yang tepat untuk mendukung tujuan organisasi. Artinya ketika personil kunci atau pimpinan meninggalkan posisinya, ada keberlanjutan manajemen sehingga tidak akan ada penghambat yang terjadi pada organisasi. Untuk memperoleh kesempatan yang setara dan lebih luas bagi karyawan dalam pengembangan karier. Untuk memperoleh sarana perwujudan aktualisasi diri dengan mendapatkan pendampingan yang intensif dari Mentor. Diharapkan seorang pemimpin memahami dan mampu menganalisis masalah yang dihadapi bawahannya serta memberikan solusi dengan metode baru, mengeksplorasi keadaan sesuai dengan visi, misi, dan tujuan organisasi. Diharapkan pimpinan Biro Kepegawaian atau Biro Sumber Daya Manusia Kementerian Agama lebih memperhatikan dan menganalisis kebutuhan pelatihan karyawan, penyesuaian bentuk pelatihan dengan usia karyawan, menentukan tujuan pelatihan, merumuskan prinsip-prinsip pembelajaran yang akan diterapkan, merumuskan muatan pelatihan, merencanakan pelaksanaan pelatihan dan implementasi, serta evaluasi pelatihan. Khususnya menambah jumlah training (pelatihan) yang dapat dilakukan dalam Biro pada Kementerian Agama Jakarta Pusat, di antaranya: program On-The-Job Training (mentoring, job assignment, job shadowing, penugasan khusus) ataupun Off-The-Job Training (class training, leadership sharing session, diklat, seminar, workshop, studi banding). 


\section{PUSTAKA ACUAN}

Afzali, A., Motahari, A. A., \& Hatami-Shirkouhi, L. (2014). Investigating The Influence of Perceived Organizational Support, Psychological Empowerment and Organizational Learning on Job Peformance: An Empirical Investigation. 21(3), 623-629.

Ali, F., Omar, R., \& Amin, M. (2013). An examination of the relationships between physical environment, perceived value, image and behavioural Intentions: A SEM approach towards Malaysian. Journal of Hotel and Tourism Management, 27, 9-26.

Ali, Z., \& Mehreen, A. (2019). Understanding succession planning as a combating strategy for turnover intentions. Journal of Advances in Management Research, 16(2), 216-233. https://doi.org/10.1108/JAMR-09-2018-0076

Amankwaa, A., \& Anku-Tsede, O. (2015). Linking Transformational Leadership to Employee Turnover: The Moderating Role of Alternative Job Opportunity. International Journal of Business Administration, 6(4). https://doi.org/10.5430/ijba.v6n4p19

Brendan Sweeney, Q. I. P.-D. F. (2013). Success through Succession: A Review of Recent Literature.

Cheung, M. F. Y., \& Wong, C. S. (2011). Transformational leadership, leader support, and employee creativity. Leadership \& Organization Development Journal, 32(7), 656-672. https://doi.org/10.1108/01437731111169988

Davenport, S., Committee, R., Chairperson, C., Management, A., Faculty, D. S., Member, C., ... Riedel, E. (2012). Walden University.

Govender, I. (2010). Succession Planning as a tool to minimise staff turnover rate: A case study of Nedbank Homeloans ' KZN operations . (June).

Gyensare, M. A., Anku-Tsede, O., Sanda, M.-A., \& Okpoti, C. A. (2016). Transformational leadership and employee turnover intention. World Journal of Entrepreneurship, Management and Sustainable Development, 12(3), 243-266. https://doi.org/10.1108/ wjemsd-02-2016-0008

Gyensare, M. A., Kumedzro, L. E., Sanda, A., \& Boso, N. (2017). Linking transformational leadership to turnover intention in the public sector: The influences of engagement, affective commitment and psychological climate. African Journal of Economic and Management Studies, 8(3), 314-337. https://doi.org/10.1108/AJEMS-07-2016-0099

Hair, J.F. Jr., R.E. Anderson, R. L. T. \& W. C. B. (2009). Multivariate Data Analysis (7 Edition). New Jersey: Perason Prentice-Hall Int.

Huang, W. R., \& Su, C. H. (2016). The mediating role of job satisfaction in the relationship between job training satisfaction and turnover intentions. Industrial and Commercial Training, 48(1), 42-52. https://doi.org/10.1108/ICT-04-2015-0029

Jehanzeb, K., Rasheed, A., \& Rasheed, M. F. (2013). Organizational Commitment and Turnover Intentions: Impact of Employee's Training in Private Sector of Saudi Arabia. International Journal of Business and Management, 8(8), 79-90. https://doi. org/10.5539/ijbm.v8n8p79

Jenderal, K. A. R. I. B. K. S. (2018). PNS Kementerian Agama dalam Angka. Retrieved from http://simpeg.kemenag.go.id 
Jha, S., \& Malviya, V. (2017). Impact of transformational leadership on employee engagement. Pranjana:The Journal of Management Awareness, 20(2), 15. https://doi.org/10.5958/09740945.2017.00011.5

Long, C. S., Thean, L. Y., Ismail, W. K. W., \& Jusoh, A. (2012). Leadership styles and employees' turnover intention: Exploratory study of academic staff in a Malaysian college. World Applied Sciences Journal, 19(4), 575-581. https://doi.org/10.5829/idosi.wasj.2012.19.04.155

Lu, L., Lu, A. C. C., Gursoy, D., \& Neale, N. R. (2016). Work engagement, job satisfaction, and turnover intentions: A comparison between supervisors and line-level employees. International Journal of Contemporary Hospitality Management, 28(4), 737-761. https:// doi.org/10.1108/IJCHM-07-2014-0360

Malek, K., Kline, S. F., \& DiPietro, R. (2018). The impact of manager training on employee turnover intentions. Journal of Hospitality and Tourism Insights, 1(3), 203-219. https:// doi.org/10.1108/jhti-02-2018-0010

Mehrabani, S. E., \& Mohamad, N. A. (2011). Succession Planning: A Necessary Process in Today's Organization. International Journal of E-Education, e-Business, e-Management and e-Learning, 1(5). https://doi.org/10.7763/ijeeee.2011.v1.61

Memon, M. A., Sallaeh, R., Baharom, M. N. R., Md Nordin, S., \& Ting, H. (2017). The relationship between training satisfaction, organisational citizenship behaviour, and turnover intention: A PLS-SEM approach. Journal of Organizational Effectiveness, 4(3), 267-290. https://doi.org/10.1108/JOEPP-03-2017-0025

Memon, M. A., Salleh, R., \& Baharom, M. N. R. (2016). The link between training satisfaction, work engagement and turnover intention. European Journal of Training and Development, 40(6), 407-429. https://doi.org/10.1108/EJTD-10-2015-0077

Mittal, S. (2016). Effects of transformational leadership on turnover intentions in IT SMEs. International Journal of Manpower, 37(8), 1322-1346. https://doi.org/10.1108/IJM10-2014-0202

Nissan, J., \& Eder, P. (1995). Practicing OD. Evaluation Review, 49(3), 76-84. https://doi. org/10.1177/0193841X9501900506

Oh, J., \& Oh, S. (2017). Authentic leadership and turnover intention: does organizational size matter? Leadership and Organization Development Journal, 38(7), 912-926. https://doi. org/10.1108/LODJ-08-2016-0209

Payne, R. A., Hovarter, R., Howell, M., Draws, C., \& Gieryn, D. (2018). Succession Planning in Public Health: Addressing Continuity, Costs, and Compliance. Nurse Leader, 16(4), 253-256. https://doi.org/10.1016/j.mnl.2018.05.008

Reeves, T. Z. (2010). Mentoring Programs in Succession Planning. State and Local Government Review, 42(1), 61-66. https://doi.org/10.1177/0160323x10368036

Romadhon, R. W., \& Indonesia, U. I. (2018). Analisis Pengaruh Training Satisfaction dan Psychological Empowerment terhadap Work Engagement dan Turnover Intention Analisis Pengaruh Training Satisfaction dan Psychological Empowerment terhadap Work Engagement dan Turnover Intention Bidang Kosentrasi: (October). https://doi. org/10.13140/RG.2.2.23222.75841 
Tayal, R., Kumar Upadhya, R., Yadav, M., Rangnekar, S., \& Singh, R. (2018). The impact of transformational leadership on employees' acceptance to change: Mediating effects of innovative behaviour and moderating effect of the use of information technology. VINE Journal of Information and Knowledge Management Systems, 48(4), 559-578. https:// doi.org/10.1108/VJIKMS-05-2018-0039

Wahyuni, A. S., Zaika, Y., Anwar, R., Brawijaya, U., \& Timur, J. (2014). Analisis Faktor-Faktor Yang Mempengaruhi Turnover Intention (Keinginan Berpindah) Karyawan. Jurnal Rekayasa Sipil, 8(2), 89-95. 